order enables urgent treatment to be initiated; this should be followed by a case conference. In most cases application will need to be made to the juvenile court for a care or supervision order to ensure continuing compliance with the diet and attendance at follow-up for assessment of growth and nutritional state. The order should be maintained until the child is no longer at risk. In the three cases in which we thought a court order necessary, once it had been obtained we were able to negotiate a nutritionally sound, if rather unusual, diet for the children and then allow them to return home knowing that adequate supervision could be maintained.

We should like to thank our dietitians Miss Ann Jenner and Miss
Dorothy Francis for their advice and help, and our medical social workers Miss Valerie Sheldon and Miss Gwen Duthie for their help and support.

\section{References}

${ }^{1}$ Barnes, L A, et al, Pediatrics, 1977, 59, 460.

2 Robson, J R K, Pediatric Clinics of North America, 1977, 24, 189.

3 Shull, M W, et al, Pediatrics, 1977, 60, 410.

4 Robson, J R K, Pediatrics, 1974, 53, 326.

5 Berkelhamer, J E, Thorp, F K, and Cobbs, S, American fournal of Diseases of Children, 1975, 129, 1240.

\title{
Comparison of intravenous and oral high-dose methotrexate in treatment of solid tumours
}

\author{
N CHRISTOPHIDIS, F J E VAJDA, I LUCAS, W J MOON, W J LOUIS
}

British Medical fournal, 1979, 1, 298-300

\section{Summary and conclusions}

An outpatient regimen of oral high-dose methotrexate was studied in 14 patients with solid tumours over 12 months. Detailed pharmacokinetic analysis in five patients showed high oral bioavailability (mean SE of mean $87.6 \pm 1.5 \%$ ), indicating that with this regimen oral methotrexate was well absorbed and the first-pass effect low. Oral administration resulted in peak plasma methotrexate concentrations of $8.4+0.5 \mu \mathrm{mol} / 1 \mathbf{~ ( 3 8 2} \pm 23$ $\mu \mathrm{g} / 100 \mathrm{ml}$ ) and was almost as effective as intravenous administration, which achieved peak concentrations of $9.9 \pm 0.4 \mu \mathrm{mol} / 1(450 \pm 18 \mu \mathrm{g} / 100 \mathrm{ml})$. In all 14 patients the clinical response to oral treatment was comparable to that reported to intravenous administration of high-dose methotrexate used in combination with other cytotoxic drugs. The disease-free interval in cases of adult sarcoma was $7.4 \pm 1.3$ months and the relapse rate $29 \%$. Out of four patients with small-cell carcinoma, two showed an objective response to oral treatment.

We suggest that oral high-dose methotrexate given in divided doses is a rational alternative to expensive intravenous high-dose methotrexate regimens, but further clinical evaluation is necessary.

\section{Introduction}

Recent correspondence suggests that substantial disagreement exists about the absorption of high oral doses of methotrexate. ${ }^{1-4}$ It has been reported that although small oral doses of methotrex-

\footnotetext{
Clinical Pharmacology and Therapeutics Unit, University of Melbourne, Austin Hospital, Heidelberg, Victoria 3084, Australia N CHRISTOPHIDIS, MB, BS, NHMRC postgraduate scholar F J E VAJDA, MD, FRACP, senior clinical pharmacologist I LUCAS, PHC, Roche research fellow

W J MOON, FRACP, clinical oncologist

W J LOUIS, MD, FRACP, professor of clinical pharmacology and therapeutics
}

ate are well absorbed, larger doses (above $80 \mathrm{mg} / \mathrm{m}^{2}$ ) are poorly absorbed and metabolised by the liver. ${ }^{4-6}$ This has led to the widespread use of parenteral routes when high-dose methotrexate followed by folinic-acid "rescue" is used to treat various solid malignant tumours. ${ }^{i-9}$ Intravenous treatment has the dual disadvantage of needing to be carried out on an inpatient basis and substantially increasing the costs of drug treatment. Bell et $a l^{3}$ recommended a modified oral high-dose $(400 \mathrm{mg})$ methotrexate regimen with folinic-acid rescue for treating solid tumours. In the past 12 months we have used a similar method of administering high-dose $(800 \mathrm{mg})$ methotrexate by mouth followed by folinic-acid rescue, which so far has given a clinical response rate comparable to that of high-dose intravenous treatment. We report here our results.

\section{Patients and methods}

Patients-We treated 14 patients with the proposed dose schedule. They comprised 12 men and two women with a mean ( \pm SE of mean) age of $44 \cdot 4 \pm 5 \cdot 0$ years, body weight $68 \cdot 2 \pm 3 \cdot 1 \mathrm{~kg}$, and body surface area $1.8 \pm 0.05 \mathrm{~m}^{2}$. Ten patients had adult sarcomas, three of which were at an advanced stage with metastases, and in seven the disease was localised and treated initially with surgery or radiotherapy or both. In these seven patients chemotherapy was an adjuvant to prior local treatment. The remaining four patients had inoperable small-cell carcinoma of the lung.

Chemotherapy-A course of chemotherapy consisted of $800 \mathrm{mg}$ of methotrexate given in combination with cyclophosphamide $(250 \mathrm{mg} /$ $\left.\mathrm{m}^{2}\right)$, adriamycin $(1 \mathrm{mg} / \mathrm{kg})$, and vincristine $\left(1 \mathrm{mg} / \mathrm{m}^{2}\right)$, and was given at four-week intervals. Methotrexate was given on day 1 of each course, followed on day 2 by the rest of the combination therapy. Peripheral white cell and platelet counts and renal and liver function tests were performed before each treatment and repeated on days 3 and 10 of each course. On the first occasion methotrexate was given intravenously as a continuous infusion over 16 hours. Subsequently the same dose of methotrexate was given by mouth $(50 \mathrm{mg}$ each hour for 16 hours) on an outpatient basis. Eight hours after completing the methotrexate administration folinic acid (Leucovorin) was started in a dose of $15 \mathrm{mg}$ by mouth four times daily and $6 \mathrm{mg}$ intramuscularly daily for two days. Cyclophosphamide, vincristine, and adriamycin were given intravenously in the outpatient clinic on day 2 .

Pharmacokinetic studies-We studied five patients with normal creatinine clearances. Plasma samples were collected via an indwelling intravenous catheter and stored at $-20^{\circ} \mathrm{C}$ until assayed for methotrexate. Sampling times were 15 minutes before the dose and then at two-hour intervals for the first 20 hours and at four- to 12-hour 
intervals for 154 hours after the initial oral dose or the start of the intravenous infusion. Urine was collected over the whole of this period at intervals of six to 24 hours. The collection times, volumes, and $\mathrm{pH}$ of samples were recorded. Aliquots were stored at $-20^{\circ} \mathrm{C}$ until assayed for methotrexate, and the amount of methotrexate excreted over the collection period was calculated. Methotrexate was measured in plasma and urine samples by a competitive protein-binding assay method $^{10}$ (New England Enzyme Centre Kit MTX 102).

Calculations - We estimated the oral bioavailability of methotrexate in each patient by dividing the area under the plasma concentration time curves after oral administration by that after intravenous administration and multiplying by 100 . The area under the curve was calculated by the trapezoidal method using a desk-top calculator (Hewlett Packard, HP97). A further estimate of bioavailability was obtained by comparing the total urinary recovery of methotrexate after both routes of administration, since metabolism of methotrexate is almost negligible and renal excretion accounts for over $90^{\circ}$ o of its elimination after intravenous administration. The plasma half life of methotrexate during the elimination phase in each patient was determined from the slope of the exponential curve of best fit, using the formula half life $=0.693 /$ slope. Curve fitting was achieved by a computer program using the least-squares technique. All results are given as means $\pm \mathrm{SE}$ of mean.

\section{Results}

PHARMACOKINETICS

The table shows the peak plasma concentrations, elimination-phase plasma half life, areas under the plasma concentration time curves, and oral bioavailability of methotrexate in five of the patients given 800 mg of methotrexate intravenously on one occasion and by mouth on another. The mean peak plasma concentration after intravenous administration was $9 \cdot 9 \pm 0 \cdot 4 \mu \mathrm{mol} / \mathrm{l}(450 \pm 18 \mu \mathrm{g} / 100 \mathrm{ml})$, while that after oral administration was $8 \cdot 4 \pm 0.5 \mu \mathrm{mol} / 1(382 \pm 23 \mu \mathrm{g} / 100 \mathrm{ml})$. In four of the five patients the elimination-phase half life was significantly longer after oral than after intravenous administration $(t=2 \cdot 33$, $\mathrm{P}<0.05)$, and the oral bioavailability determined from the plasma data by the method using the area under the curve ranged from $82 \%$ to $91 \%$ (mean $=87.6 \%$ ). Accurate urine collections under the conditions of the study were difficult. Despite this, after oral and intravenous administration the urinary recovery of methotrexate ranged from $63 \%$ to $90^{\circ} \%$, over half being recovered in the first 32 hours.

The range of 48-hour plasma concentrations during outpatient treatment with methotrexate was $0-5.06 \mu \mathrm{mol} / 1(0-230 \mu \mathrm{g} / 100 \mathrm{ml})$, the mean concentration being $1 \cdot 39 \pm 0.22 \mu \mathrm{mol} / \mathrm{l}(63 \pm 10 \mu \mathrm{g} / 100 \mathrm{ml})$. Whenever the plasma concentration of methotrexate at 48 hours exceeded $2 \cdot 2 \mu \mathrm{mol} / 1(100 \mu \mathrm{g} / 100 \mathrm{ml})$ the rescue programme was extended for an extra two days. One patient has recently shown persistently indetectable methotrexate concentrations suggesting poor compliance and will now be treated as an inpatient under closer supervision.

\section{CLINICAL RESPONSE}

Treatment was well tolerated as evidenced by the low incidence of nausea and vomiting during the 16 hours of oral methotrexate administration. Most of the gastrointestinal discomfort occurred after day 2, during administration of cyclophosphamide, adriamycin, and vincristine. No toxicity in the form of oral mucositis, bone-marrow suppression, or renal toxicity occurred.

The disease-free interval in the seven patients with primary adult sarcoma ranged from one to 11 months (mean $7 \cdot 4 \pm 1.3$ months), with a relapse rate of $29 \%(2 / 7)$ during a mean follow-up period of eight months. In the patients with metastatic adult sarcoma, a complete response lasting three months was noted in one, a partial response after two courses of treatment in another, and no response in the third, who had osteogenic sarcoma with pulmonary metastases on presentation. Of the four patients with small-cell carcinoma of the lung, two were alive nine months after the start of chemotherapy; another, who had cerebral metastases on presentation, died 8.5 months after starting chemotherapy; and the fourth was alive after two months. Only two of the four patients showed a greater than $50 \%$ reduction in tumour size on chest $x$-ray examination. Thus the response rate was $50 \%$ with a mean duration of survival of seven months up to the end of the study.

\section{Discussion}

The rationale behind high-dose methotrexate treatment regimens is to produce an antitumour effect with high extracellular concentrations of methotrexate. ${ }^{11}$ In-vitro experiments with animal tumour cells ${ }^{12}$ showed that at a free intracellular concentration of methotrexate of $3 \mu \mathrm{mol} / 1(136 \mu \mathrm{g} / 100 \mathrm{ml})$ tetrahydrofolate production was totally inhibited. For this to be achieved an extracellular concentration of methotrexate of the order of $100 \mu \mathrm{mol} / \mathrm{l}(4544 \mu \mathrm{g} / 100 \mathrm{ml})$ was required. In the presence of vincristine, however, the extracellular concentration of methotrexate required to inhibit tetrahydrofolate production was of the order of only $5 \mu \mathrm{mol} / 1(227 \mu \mathrm{g} / 100 \mathrm{ml})$. This was achieved with our oral regimen, which included vincristine.

The oral dose schedule of methotrexate used in these studies was influenced by reports in which oral bioavailability was estimated using radioactively labelled methotrexate. These studies suggest that oral bioavailability decreases when doses above $50 \mathrm{mg}$ are used. The methods used in our study permit direct measurement of methotrexate and indicate that administration of $800 \mathrm{mg}$ of methotrexate by hourly oral administration of $50 \mathrm{mg}$ doses resulted in a bioavailability of over $80 \%$ in all patients.

Chabner et al $^{13}$ showed in animals, and others ${ }^{14-16}$ in man, that host toxicity correlates with prolonged low plasma concentrations of methotrexate during the elimination phase of the plasma concentration time curves. Folinic acid is given during this phase to prevent toxicity. We routinely measured plasma methotrexate concentrations at 48 hours during this phase and found mean values of $1.39 \pm 0.22 \mu \mathrm{mol} / 1(63 \pm 10 \mu \mathrm{g} / 100 \mathrm{ml})$. Whenever individual methotrexate concentrations exceeded $2.2 \mu \mathrm{mol} / 1(100 \mu \mathrm{g} / 100 \mathrm{ml})$ the rescue programme was extended, and with this protocol no serious toxicity occurred.

The number of patients treated was small but so far the antitumour effectiveness of the proposed regimen has been comparable to that achieved with more established treatment programmes that include intravenous administration of high

Comparison of peak plasma concentrations, elimination half lives, and areas under plasma concentration time curves in five patients after administration of 800 mg of methotrexate by mouth or intravenous infusion over 16 hours

\begin{tabular}{|c|c|c|c|c|c|c|c|}
\hline \multirow{2}{*}{$\begin{array}{l}\text { Case } \\
\text { No }\end{array}$} & \multicolumn{2}{|c|}{$\begin{array}{l}\text { Peak plasma methotrexate } \\
\qquad(\mu \mathrm{mol} / 1)\end{array}$} & \multicolumn{2}{|c|}{$\begin{array}{c}\text { Elimination-phase plasma half life } \\
\text { (hours) }\end{array}$} & \multicolumn{2}{|c|}{$\begin{array}{l}\text { Area under curve } \\
(\mu \mathrm{mol} \mathrm{h} / 1)\end{array}$} & \multirow{2}{*}{$\begin{array}{c}\text { Oral } \\
\text { bioavailability } \\
(\%)\end{array}$} \\
\hline & IV & Oral & IV & Oral & IV & Oral & \\
\hline $\begin{array}{l}1 \\
2 \\
3 \\
4 \\
5 \\
\end{array}$ & $\begin{array}{r}10 \cdot 3 \\
8 \cdot 4 \\
10 \cdot 6 \\
9 \cdot 7 \\
10 \cdot 3\end{array}$ & $\begin{array}{l}9 \cdot 5 \\
6 \cdot 6 \\
9 \cdot 2 \\
8 \cdot 4 \\
8 \cdot 4\end{array}$ & $\begin{array}{l}21 \cdot 0 \\
16 \cdot 1 \\
18 \cdot 2 \\
19 \cdot 8 \\
19.8\end{array}$ & $\begin{array}{l}23 \cdot 1 \\
21 \cdot 7 \\
21 \cdot 0 \\
19 \cdot 3 \\
28 \cdot 9\end{array}$ & $\begin{array}{l}301.9 \\
251.5 \\
313.2 \\
310.1 \\
317.8\end{array}$ & $\begin{array}{l}265 \cdot 2 \\
220.7 \\
282.6 \\
253.5 \\
287.6\end{array}$ & $\begin{array}{l}87 \cdot 8 \\
87 \cdot 3 \\
90 \cdot 2 \\
82 \cdot 3 \\
90 \cdot 5\end{array}$ \\
\hline Mean $\pm S E$ of mean & $9 \cdot 9 \pm 0 \cdot 4$ & $8.4 \pm 0.5$ & $18 \cdot 8 \pm 1 \cdot 1$ & $22 \cdot 8 \pm 1 \cdot 6$ & $298 \cdot 9 \pm 12 \cdot 1$ & $261.9 \pm 11 \cdot 9$ & $87 \cdot 6 \pm 1 \cdot 5$ \\
\hline
\end{tabular}

IV = Intravenous.

Conversion: SI to traditional units-Methotrexate: $1 \mu \mathrm{mol} / 1 \approx 45.44 \mu \mathrm{g} / 100 \mathrm{ml}$. 
doses of methotrexate combined with other cytotoxic drugs. Seven out of 10 patients with localised adult sarcomas were free of disease for a mean interval of 7.3 months. This is comparable with the results of Townsend et $a l,{ }^{17}$ who used adjuvant chemotherapy with adriamycin and high-dose methotrexate given intravenously and found that $68 \%$ of patients with adult sarcoma were disease free after a mean follow-up period of 9.3 months. Of four patients with small-cell carcinoma of the lung treated with the present schedule, two showed objective response, a rate similar to that reported by Gilby et $a l,{ }^{18}$ who used a similar combination of drugs including high-dose intravenous methotrexate (200 mg over 24 hours), vincristine, adriamycin, cyclophosphamide, and prednisolone combined with radiotherapy.

We have shown that our regimen may be safely administered on an outpatient basis with the co-operation of a home-visiting nursing service. The plasma concentrations achieved and the bioavailability of methotrexate given by mouth with this method are comparable to those after intravenous administration, and extrapolation from in-vitro studies on malignant cells indicates that the plasma concentrations achieved are adequate for an antitumour effect. Patient tolerance was good and the cost of treatment considerably reduced. These data provide a sound pharmacokinetic basis for further clinical evaluation of modified high-dose oral methotrexate regimens.
This study was supported by a Grant-in-Aid from the Anti-Cancer Council of Victoria.

\section{References}

${ }^{1}$ Palmer, B V, British Medical fournal, 1977, 2, 1354.

2 Price, L A, and Goldie, J H, British Medical fournal, 1977, 2, 1603.

${ }^{3}$ Bell, R, et al, British Medical fournal, 1978, 1, 857.

* Hill, G W R, and Roach, M, British Medical fournal, 1978, 1, 1140.

${ }^{5}$ Henderson, E S, Adamson, R H, and Oliverio, V T, Cancer Research, $1965,25,1018$

6 Wan, S H, et al, Cancer Research, 1974, 34, 3487.

7 Dierassi, I, et al, Cancer, 1972, 30, 22.

${ }^{8} \mathrm{Jaffe}, \mathrm{N}$, Cancer, 1972, 30, 1627.

9 Vincent, R G, et al, Cancer, 1975, 36, 873.

${ }^{10}$ Myers, C E, et al, Proceedings of the National Academy of Sciences, 1975, 72, 3683.

${ }^{11}$ Frie, E, et al, New England fournal of Medicine, 1975, 292, 846.

12 Goldman, D, et al, Cancer Research, 1976, 36, 276.

${ }^{13}$ Chabner, B A, and Young, R C, Fournal of Clinical Investigation, 1973, 52, 1804.

14 Stoller, R G, et al, New England fournal of Medicine, 1977, 297, 630.

15 Salasoo, S, et al, Medical fournal of Australia, 1976, 1, 777.

${ }_{16}$ Pitman, S W, and Frei, E, Cancer Treatment Reports, 1977, 61, 695.

17 Townsend, C M, Eilber, F R, and Morton, D L, Proceedings of the American Association for Cancer Research, 1976, 17, 265.

18 Gilby, E D, et al, Cancer, 1977, 39, 1959.

\title{
Urinary excretion of factor VIII after renal transplantation
}

\author{
Z M RUGGERI, Y B GORDON, NICOLE ARDAILLOU, MARIE-JOSÉ LARRIEU, A TARANTINO, \\ RAFFAELLA COPPOLA, C PONTICELLI, P M MANNUCCI
}

British Medical fournal, 1979, 1, 300-303

\section{Summary and conclusions}

The urinary excretion of factor-VIII-related antigen (VIIIRAg) was measured in 72 patients with kidney transplants and compared with that of two end-products of fibrin-fibrinogen lysis (fragments $D$ and $E$ ) to assess their usefulness in monitoring the onset of rejection episodes. Specific and sensitive radioimmunoassays were used to measure the three proteins. Unconcentrated urine samples of 24-hour collections were obtained from 20 healthy subjects, 48 patients with stable transplants,

Haemophilia and Thrombosis Centre "Angelo Bianchi Bonomi" and Third Department of Internal Medicine, University of Milan and Policlinico Hospital, Milan

Z M RUGGERI, MD, senior registrar

RAFFAELLA COPPOLA, BSC, research assistant

P M MANNUCCI, MD, professor

Department of Reproductive Physiology, St Bartholomew's Hospital, London

Y B GORDON, MD, MRCOG, consultant

Institut de Pathologie Cellulaire (Inserm U143), Hôpital de Bicêtre, Paris

NICOLE ARDAILLOU, MD, senior research assistant

MARIE-JOSÉ LARRIEU, MD, professor

Division of Nephrology and Dialysis, Policlinico Hospital, Milan A TARANTINO, MD, senior registrar

C PONTICELLI, MD, consultant and 24 patients with recent transplants serially followed up from the day of transplantation. Factor VIIIRAg and fragments $E$ and $D$ were not detectable in the urine from healthy subjects but were present in $39 \%, 60 \%$, and $100 \%$ respectively of samples from patients with stable transplants. During 33 acute rejection episodes in 19 patients with recent transplants factor VIIIRAg and fragments $E$ and $D$ were significantly increased above the values observed in patients with stable transplants in $82 \%, 73 \%$, and $64 \%$ of samples respectively; in patients with recent transplants showing no clinical sign of rejection increased excretion of these proteins was observed in $11 \%, 26 \%$, and $22 \%$ of samples respectively. The presence of factor VIIIRAg in urine from patients with kidney allografts suggests that endothelial cellfactor VIII-platelet interactions might pay a key part in the pathogenesis of acute rejection.

The results suggest that the assay of factor VIIIRAg in urine is more useful than assays of fragments $D$ and $E$ as a corroborative index of transplant rejection.

\section{Introduction}

Studies on $\operatorname{man}^{12}$ and animals ${ }^{3}{ }^{4}$ have shown the existence of local activation of the coagulation pathway during acute and hyperacute rejection of renal allografts. In addition, urinary excretion of fibrin-fibrinogen degradation products (FDP), which are considered to be an index of secondary activation of the fibrinolytic system after fibrin deposition, was shown to be increased during acute rejection and its measurement thought to be of predictive diagnostic value. ${ }^{5-11}$

In the sequence of pathological reactions leading to transplant 